\title{
Para-aortic Lymph Node Invasion in High-risk Endometrial Cancer: Performance of ${ }^{18}$ FDG PET-CT
}

\author{
MAXIME LEGROS ${ }^{1}$, FRANÇOIS MARGUERITTE ${ }^{1}$, ANTOINE TARDIEU ${ }^{1}$, \\ ELISE DELUCHE ${ }^{2}$, VALERE BELLE MBOU ${ }^{3}$, AYMELINE LACORRE ${ }^{1}$, ALEXANDRU CEUCA $^{4}$, \\ YVES AUBARD ${ }^{1}$, JACQUES MONTEIL $^{5}$, CAMILLE SALLEE ${ }^{1}$ and TRISTAN GAUTHIER ${ }^{1}$ \\ ${ }^{1}$ Department of Gynecology and Obstetrics, University Hospital Center of Limoges, Limoges, France; \\ ${ }^{2}$ Department of Medical Oncology, University Hospital Center of Limoges, Limoges, France; \\ ${ }^{3}$ Department of Pathology, University Hospital Center of Limoges, Limoges, France; \\ ${ }^{4}$ Department of Radiology, University Hospital Center of Limoges, Limoges, France; \\ ${ }^{5}$ Department of Nuclear Medicine, University Hospital Center of Limoges, Limoges, France
}

\begin{abstract}
Aim: ${ }^{18}$ F-Fluorodeoxyglucose positron-emission tomography integrated with computed tomography $\left({ }^{18} \mathrm{FDG}\right.$ PET-CT) is a non-invasive examination that could be helpful for the management of endometrial cancer. This study investigated the performance of ${ }^{18} F D G$ PET-CT in assessing para-aortic (PA) lymph-node involvement in high-risk endometrial cancer. Materials and Methods: This was a retrospective, single-center study carried out between 2009 and 2018. The inclusion criteria were high-risk and locally advanced type 1 or 2 endometrial cancer with ${ }^{18} F D G$ PETCT before PA lymphadenectomy. Results: During the study period, among 142 patients with high-risk endometrial cancer, 35 patients (24.6\%) underwent ${ }^{18}$ FDG PET-CT followed by $P A$ lymphadenectomy. In $25 \%$ of cases, PA lymphadenectomy was not performed due to the discovery of metastasis. ${ }^{18} \mathrm{FDG}$ PET-CT had a sensitivity of 50\%, a specificity of $100 \%$, a positive predictive value of $100 \%$, a negative predictive value of $75 \%$, accuracy of $80 \%$ and an area under the curve of 0.75 for the evaluation of PA involvement. Conclusion: According to its high specificity in PA lymph-node evaluation, a positive PET scan might allow PA lymphadenectomy to be avoided.
\end{abstract}

Endometrial cancer is the fourth most frequent cancer in women, with more than 8,000 cases per year in France (1). A knowledge of lymph-node status and International Federation of Gynecology and Obstetrics (FIGO) stage is necessary to establish the most appropriate treatment

Correspondence to: Maxime Legros, Departement de Gynecologie Obstetrique, CHU limoges, 8 avenue Dominique Larrey, 87000 Limoges, France. Tel: +33 555055555, e-mail: legros.maxime12@ gmail.com

Key Words: Endometrial cancer, PET-CT, para-aortic, lymphadenectomy. strategy. The risk of lymph-node involvement is strongly correlated with the characteristics of the tumor, and depends on its histological type, grade, the degree of local extension (myometrium and cervical stroma), and the presence of lymphovascular space invasion (2). Since the European Society for Medical Oncology (ESMO) congress of 2009 (3) and the publication of the French National Institute of Cancer (INCA) recommendations in 2010 (4), para-aortic lymphadenectomy (PAL) has been recommended for stage I tumors of histological type 1 (endometrioid adenocarcinoma) with a high risk of recurrence (stage IB and grade 3, or with the presence of lymphovascular space invasion, regardless of grade), for tumors of stage II and above, and for histological type 2 tumors (clear-cell carcinoma, papillary serous carcinoma, and carcinosarcoma) of all stages.

PAL is a surgical procedure associated with non-negligible morbidity, particularly in elderly patients with associated comorbid conditions (5). Its therapeutic impact on survival is a matter of debate (6). Knowledge of pelvic and paraaortic (PA) lymph-node status guides therapeutic decisions, determining whether there are indications for more or less extensive radiotherapy and systemic treatment (7). The PORTEC-3 study showed that adjuvant chemotherapy, in addition to radiotherapy, was beneficial in stage III high-risk endometrial cancer (8).

${ }^{18}$ F-Fluorodeoxyglucose positron-emission tomography integrated with computed tomography $\left({ }^{18} \mathrm{FDG}\right.$ PET-CT $)$ is a non-invasive examination that can modify the management of endometrial cancer. It was cited in the 2016 INCA and ESMO guidelines as an option (3, 4). It is widely used in the management of locally advanced cervical cancer $(9,10)$. ${ }^{18}$ FDG PET-CT may help clinicians decide whether or not to perform lymphadenectomy in cases of endometrial cancer with an indication for PAL. Few studies have evaluated its potential utility for lymph-node staging in endometrial cancer. 
We investigated the performance of ${ }^{18}$ FDG PET-CT for assessing PA involvement in high-risk type 1 and 2 endometrial cancer.

\section{Materials and Methods}

Patients. We performed a retrospective, single-center study to evaluate the diagnostic performance of preoperative ${ }^{18}$ FDG PET-CT for assessing PA lymph-node involvement in high-risk and advanced endometrial cancer at Limoges University Hospital between 2009 and 2018. The inclusion criteria were high-risk and locally advanced type 1 or 2 endometrial cancer and the performance of ${ }^{18}$ FDG PETCT before PAL. Patients with recurrent cancer or on neoadjuvant chemotherapy were excluded.

PET-CT was not performed in patients for whom no treatment was planned due to poor general condition, or in patients for whom stage IVB disease had already been demonstrated by standard imaging.

The following data were collected: Age at diagnosis, body mass index (BMI), positivity or negativity of preoperative ${ }^{18}$ FDG PET-CT for PA lymph nodes, positivity or negativity of preoperative magnetic resonance imaging (MRI) for PA lymph nodes, surgical approach, and pathology findings (histological type, grade, presence of vascular emboli, FIGO stage, number of lymph nodes involved, and the number of lymph nodes removed). We compared the pathology results for PAL with preoperative MRI and ${ }^{18}$ FDG PET-CT findings.

All treatment decisions were taken at multidisciplinary medical team meetings, in accordance with the recommendations of the INCA and ESMO, according to the general condition of the patient.

${ }^{18} \mathrm{FDG}$ PET-CT. Patients underwent ${ }^{18} \mathrm{FDG}$ PET-CT on a SIEMENS Symbia T6 machine (from January 2009 to August 2015) or a SIEMENS Biograph mCT20 machine (since November 2015) at the Department of Nuclear Medicine, University Hospital Center of Limoges, Limoges, France. The results were interpreted by a senior nuclear physician. A second centralized reading was then performed for each ${ }^{18}$ FDG PET-CT scan.

The patients received an injection of ${ }^{18} \mathrm{FDG}(5 \mathrm{MBq} / \mathrm{kg})$. All patients fasted for at least 6 hours before the examination. Peripheral glucose concentration was systematically evaluated. ${ }^{18}$ FDG PET-CT was performed only in patients with a blood glucose concentration below $140 \mathrm{mg} / \mathrm{dl}$. PET recordings were acquired 60 to 115 minutes after the injection. Image quality and diuresis were increased by injecting $0.5 \mathrm{mg}$ of furosemide per kilogram body weight ( $40 \mathrm{mg}$ maximum) intravenously into the patients 45 minutes before data acquisition.

Lymph nodes were considered to be positive on ${ }^{18} \mathrm{FDG}$ PET-CT if FDG uptake was greater than that of the surrounding tissue in a structure corresponding to a lymph node of more than $5 \mathrm{~mm}$ in diameter localized on CT sections.

MRI. MRI was performed with a 1.5 Tesla system (Philips Achieva Best, Eindhoven, NL) and pelvis- and body-phased array antennas. For transaxial and transverse sections of the pelvis and abdomen, and for sagittal and coronal sequences, T2 spin -echo, T1 spin-echo, diffusion and $\mathrm{T} 1$ spin-echo with intravenous gadolinium injection, and fat-suppression sequences were used, with a slice thickness of $3 \mathrm{~mm}$. The criterion for lymph-node involvement on MRI was a short diameter of greater than $8 \mathrm{~mm}$ for pelvic lymph nodes and 10 $\mathrm{mm}$ for PA lymph nodes.
Pathology analysis. Lymph nodes were evaluated macroscopically and counted by a pathologist. Pathology analysis was performed according to the standard procedure, with hematoxylin-eosin-saffron staining. Slides giving false-negative results on ${ }^{18}$ FDG PET-CT were reread.

Surgical protocol. The patients underwent laparotomy, robotassisted laparoscopy, or retro- or transperitoneal laparoscopy. The choice of approach was based on BMI, age, comorbid conditions and FIGO stage. PAL extended from the left renal vein to the iliac bifurcations (including the promontory and common iliac vein). The internal, external, and obturator iliac lymph nodes were considered to lie within the zone of pelvic lymphadenectomy.

Statistical analysis. All the data were recovered from a computerized database (Filemaker Pro $13.0 \mathrm{v} 5{ }^{\circledR}{ }^{\circledR}$, FileMaker ${ }^{\circledR}$, Inc., Santa Clara, CA, USA). Quantitative data are expressed as means and ranges, and qualitative data are expressed as percentages. The diagnostic performance of ${ }^{18}$ FDG PET-CT and MRI was assessed by calculating sensitivity specificity, positive predictive value (PPV), negative predictive value (NPV), and accuracy. The gold standard evaluation was the definitive pathological examination of the PA lymph nodes.

Our main objective was to study the performance of ${ }^{18}$ FDG PETCT for evaluating PA involvement in high-risk or locally advanced endometrial cancer. Our secondary objective was to study its performance as a function of histological type.

Student's $t$-test was used for comparisons of continuous variables and Fisher's exact test was used for comparisons of categorical variables. Comparisons of two areas under the receiver operating characteristics curve (AUC) were performed with the comproc or roccomp module of STATA ${ }^{\circledR}$. McNemar or Fisher's exact test was used to compare the intrinsic characteristics of a test (according to the independence or non-independence of the samples). All analyses and calculations were performed with STATA $15.1 \mathrm{SE}^{\circledR}$ software (StataCorp, College Station, TX, USA). Values of $p<0.05$ were considered statistically significant.

\section{Results}

Between 2009 and 2018, 273 patients were treated for endometrial cancer at Limoges University Hospital, 142 (52\%) of whom had cancer with a high risk of recurrence or at an advanced stage. In total, $81(57 \%)$ out of these 142 patients underwent ${ }^{18}$ FDG PET-CT during their initial examinations, and $42(52 \%)$ of these patients did not undergo PAL (Figure 1). Among the 142 patients with high-risk endometrial cancer, $61(43 \%)$ did not undergo ${ }^{18}$ FDG PET-CT due to the optional nature of this examination or because advanced-stage cancer was identified on standard imaging examinations.

PAL was not performed in $20(25 \%)$ out of the 81 patients who underwent ${ }^{18}$ FDG PET-CT due to the discovery of metastasis. Four out of the 39 patients who underwent PAL were excluded from the study (three because they received neoadjuvant chemotherapy and one due to recurrence) (see Figure 1).

The data for the 35 patients who underwent ${ }^{18}$ FDG PET-CT followed by PAL are presented in Table I. Fourteen (40\%) had type 1 , and $21(60 \%)$ had type 2 tumors. PAL findings were 


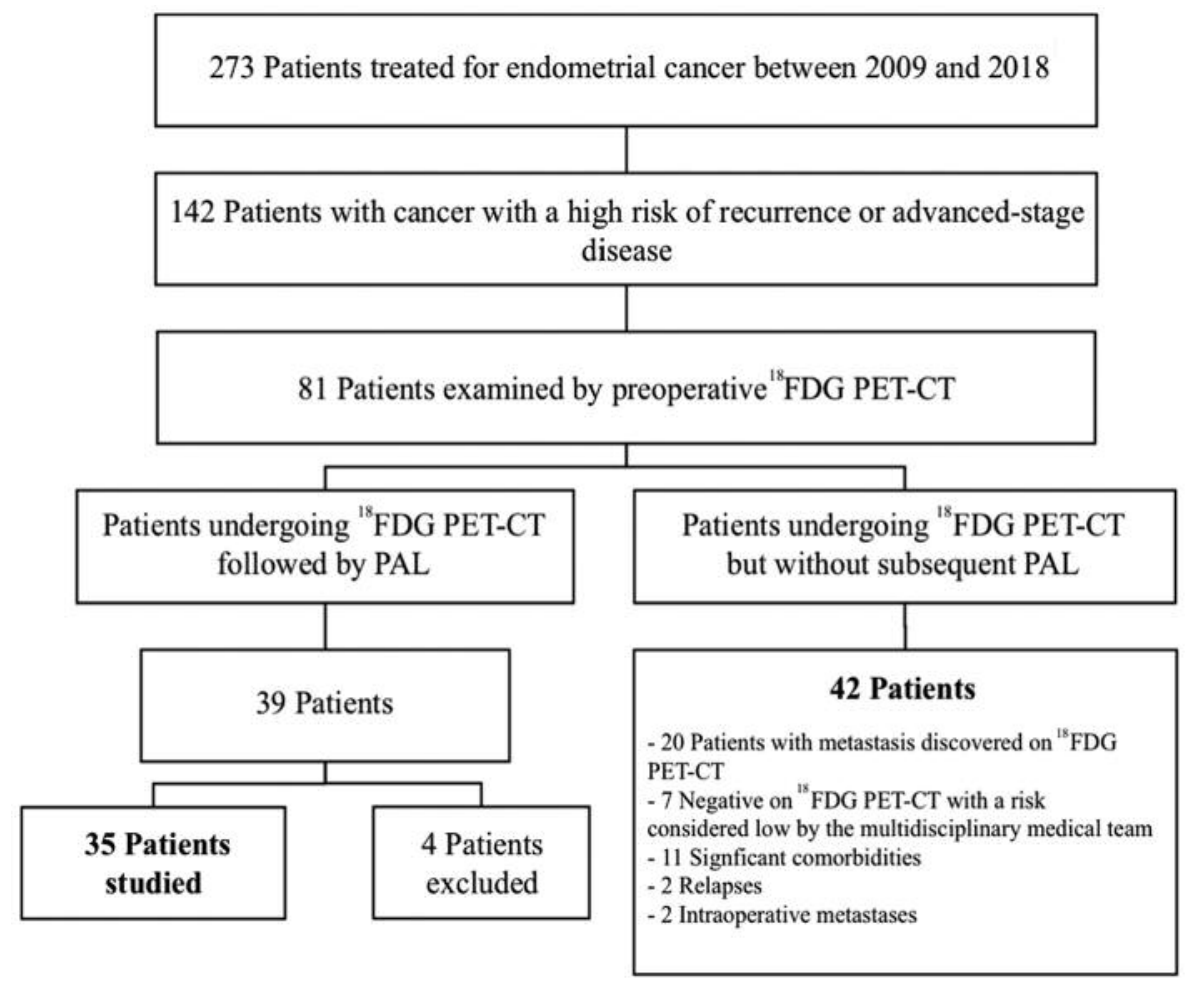

Figure 1. Flowchart of the study. ${ }^{18}$ FDG PET-CT: ${ }^{18} \mathrm{~F}$-Fluorodeoxyglucose positron-emission tomography integrated with computed tomography. PAL: para-aortic lymphadenectomy.

positive for 14 patients (40\%). The mean number of positive lymph nodes was three (range=1-12) for these patients. Eleven out of the 14 patients with positive PAL results $(78.6 \%)$ had type 2 tumors (eight papillary serous carcinomas, one clear-cell carcinoma, and two carcinosarcomas). The PA invasion rate for type 1 cancer was $21.4 \%$ and that for type 2 cancer was $52.4 \%$ $(p=0.09)$. The mean number of positive lymph nodes in cases of PA involvement was 2.7 for those with type 1 and 3.2 for those with type 2 ( $p=0.8$ ) tumors. PA lymph-node involvement was associated with pelvic lymph-node involvement in half of the cases. FIGO stage distribution differed significantly between the two histological types after complete surgical staging, especially for tumors advanced beyond stage 3 $(p=0.007)$. No significant differences in overall characteristics were found between the two groups.

${ }^{18}$ FDG PET-CT had a sensitivity of $50 \%$, specificity of $100 \%$, PPV of $100 \%$, NPV of $75 \%$, an accuracy of $80 \%$, and an AUC of 0.75 for the evaluation of PA involvement.

MRI had a sensitivity of $33.3 \%$, specificity of $100 \%$, PPV of $100 \%$, NPV of $70.4 \%$, an accuracy of $74.2 \%$, and an AUC of 0.67 for the evaluation of PA involvement. The difference in diagnostic performance between the two examinations was not significant $(p=0.13)$.

Table II shows a comparison of the performance of ${ }^{18} \mathrm{FDG}$ PET-CT for tumors of different histological types. The differences in sensitivity and in AUC according to tumor type were not significant ( $p=0.500$ and $p=0.565$, respectively).

Table III presents the main characteristics of the ${ }^{18} \mathrm{FDG}$ PET-CT scans. The mean number of positive lymph nodes was two (range $=1-5$ ) for the seven patients with false-negative ${ }^{18}$ FDG PET-CT results. Six of the false-negative tumors were of type 2 (four papillary serous carcinomas, one clear-cell carcinoma, and one carcinosarcoma), including three tumors with a preoperative stage of $1 \mathrm{~A}$. The mean lesion size for the 15 positive lymph nodes was $2.7 \mathrm{~mm}$, but three lymph nodes had lesions of more than $5 \mathrm{~mm}$ in diameter.

\section{Discussion}

${ }^{18}$ FDG PET-CT appears to be useful for evaluating PA involvement in high-risk or locally advanced endometrial cancer, given its high specificity. Its performance appeared to vary with histological type. Sensitivity and accuracy appeared lower for type 2 than for type 1 tumors, but this difference was not statistically significant: $66.7 \%$ and $92.9 \%$ for type 1 , and $45.5 \%$ and $71.4 \%$ for type 2 , respectively.

Our results are similar to the published results presented in Table IV, which summarizes the series focusing specifically on the performance of ${ }^{18}$ FDG PET-CT for the assessment of PA lymph nodes. 
Table I. Patient characteristics according to histological type.

\begin{tabular}{|c|c|c|c|c|}
\hline Characteristic & $\begin{array}{l}\text { Type } 1 \\
(\mathrm{~N}=14)\end{array}$ & $\begin{array}{l}\text { Type } 2 \\
(\mathrm{~N}=21)\end{array}$ & $\begin{array}{c}\text { Total } \\
(\mathrm{N}=35)\end{array}$ & $p$-Value \\
\hline \multicolumn{5}{|c|}{ Age at diagnosis, years } \\
\hline Mean (range) & $62.7(49-78)$ & $64.3(43-76)$ & $63.7(43-78)$ & $0.617^{*}$ \\
\hline \multicolumn{5}{|l|}{ BMI, $\mathrm{kg} / \mathrm{m}^{2}$} \\
\hline Mean (range) & $28.6(21.1-36.3)$ & $25.4(14.4-38.6)$ & $26.6(14.4-38.6)$ & $0.101^{*}$ \\
\hline \multicolumn{5}{|c|}{ Histological type, $\mathrm{n}(\%)$} \\
\hline Endometrioid & $14(100)$ & NA & $14(40.0)$ & $<0.001^{\#}$ \\
\hline Clear cell & NA & $5(23.8)$ & $5(14.3)$ & \\
\hline Carcinosarcoma & NA & $4(19.1)$ & $4(11.4)$ & \\
\hline Papillary serous & NA & $12(57.1)$ & $12(34.3)$ & \\
\hline \multicolumn{5}{|c|}{ FIGO stage (after surgery), n (\%) } \\
\hline IA & $1(7.1)$ & $6(28.6)$ & $7(20.0)$ & $0.007 \#$ \\
\hline IB & $2(14.3)$ & $2(9.5)$ & $4(11.4)$ & \\
\hline II & $2(14.3)$ & $0(0.0)$ & $2(5.7)$ & \\
\hline IIIA & $3(21.4)$ & $0(0.0)$ & $3(8.6)$ & \\
\hline IIIB & $0(0.0)$ & $1(4.8)$ & $1(2.9)$ & \\
\hline IIIC1 & $2(14.3)$ & $0(0.0)$ & $2(5.7)$ & \\
\hline IIIC2 & $3(21.4)$ & $11(52.4)$ & $14(40.0)$ & \\
\hline IVA & $0(0.0)$ & $1(4.8)$ & $1(2.9)$ & \\
\hline IVB & $1(7.1)$ & $0(0.0)$ & $1(2.9)$ & \\
\hline \multicolumn{5}{|l|}{ LVSI, n (\%) } \\
\hline Yes & $5(35.7)$ & $13(61.9)$ & $18(51.4)$ & $0.176^{\#}$ \\
\hline No & $9(64.3)$ & $8(38.1)$ & $17(48.6)$ & \\
\hline \multicolumn{5}{|l|}{ Procedure, n (\%) } \\
\hline Laparoscopy & $9(64.3)$ & $11(52.4)$ & $20(51.1)$ & $0.511^{\#}$ \\
\hline Robot-assisted & $0(0.0)$ & $3(14.3)$ & $3(8.6)$ & \\
\hline Laparotomy & $5(35.7)$ & $7(33.3)$ & $12(34.3)$ & \\
\hline Number of PALN & & & & $0.985^{*}$ \\
\hline Mean & 16.6 & 16.7 & 16.7 & \\
\hline Range & $2-46$ & $5-39$ & $2-46$ & \\
\hline
\end{tabular}

NA: Not applicable; BMI: body mass index; FIGO: International Federation of Gynecology and Obstetrics; LVSI: lymphovascular space invasion; PALN: para-aortic lymph node. *Student's $t$-test, ${ }^{*}$ Fisher's exact test.

Our study is original in that it is the only study to date as far as we are aware to have focused on the performance of ${ }^{18} \mathrm{FDG}$ PET-CT according to histological type. In previous studies evaluating the performance of ${ }^{18}$ FDG PET-CT, particularly in the large series of Atri et al. (16), the proportion of type 2 tumors was not clearly stated. Our series revealed a trend towards lower accuracy for type 2 tumors than for type 1 tumors. The high proportion of type 2 lesions in our series and the high rate of PA lymph-node involvement may account for the lower accuracy in this study than in previous studies. Indeed, the extrinsic diagnostic qualities (PPV, NPV, and accuracy) of this technique vary with disease prevalence, whereas the intrinsic diagnostic qualities of the test (sensitivity and specificity) are independent of disease prevalence. Furthermore, the study by Park et al. (12) performed in 2008, that included $39.6 \%$ type 2 lesions, had one of the lowest accuracy rates of the published reports, although the exact proportion of type 2 lesions in patients undergoing PAL was not stated.

We currently have no reasonable explanation for this difference in performance according to histological type.
Table II. Comparison of the performance of ${ }^{18} \mathrm{~F}$-fluorodeoxyglucose positron-emission tomography integrated with computed tomography $\left({ }^{18}\right.$ FDG PET-CT) for tumors of different histological types.

\begin{tabular}{lrrr}
\hline Performance of 18FDG PET-CT & Type 1 & Type 2 & $p$-Value \\
\hline Sensitivity & $66.7 \%$ & $45.5 \%$ & 0.500 \\
Specificity & $100.0 \%$ & $100.0 \%$ & \\
PPV & $100.0 \%$ & $100.0 \%$ & \\
NPV & $91.7 \%$ & $62.5 \%$ & \\
Accuracy & $92.9 \%$ & $71.4 \%$ & \\
AUC & 0.833 & 0.727 & 0.565 \\
\hline
\end{tabular}

PPV: Positive predictive value; NPV: negative predictive value; AUC: area under the receiver operating characteristics curve.

However, histological type may be a determinant of the sensitivity of ${ }^{18}$ FDG PET-CT. The cellular uptake of ${ }^{18}$ FDG appears to depend partly on cellular grade (17). In ovarian cancer, patients with clear-cell carcinoma have been shown to have a lower mean maximal standardized uptake value than 
Table III. Characteristics of the cases that were false-negative by ${ }^{18} \mathrm{~F}$-fluorodeoxyglucose positron-emission tomography integrated with computed tomography.

\begin{tabular}{|c|c|c|c|c|c|c|c|c|c|}
\hline Patient & $\begin{array}{l}\text { Age } \\
\text { (years) }\end{array}$ & $\begin{array}{c}\text { BMI } \\
\left(\mathrm{kg} / \mathrm{m}^{2}\right)\end{array}$ & $\begin{array}{l}\text { Preoperative } \\
\text { stage }^{\#}\end{array}$ & $\begin{array}{c}\text { Results of } \\
\text { PAL: N+/NT }\end{array}$ & $\begin{array}{c}\text { Involvement }(\mathrm{mm}) / \\
\text { size of lymph node }(\mathrm{mm})\end{array}$ & $\begin{array}{l}\text { Results of } \\
\text { PL: } \mathrm{N}+/ \mathrm{N}_{\mathrm{T}}\end{array}$ & $\begin{array}{l}\text { Histological } \\
\text { type }\end{array}$ & Grade & LVSI \\
\hline 1 & 63 & 33.8 & IA & $1+/ 9$ & $3 / 32$ & NP4 & Endometrioid & 2 & Yes \\
\hline 2 & 72 & 31.3 & IA & $5+/ 29$ & $1 / 3,1 / 5,1 / 9,1 / 5,1 / 4$ & $0 / 27$ & Clear cell & 3 & No \\
\hline 3 & 51 & 22.3 & IA & $2+/ 7$ & $7 / 7,6 / 6$ & $0 / 16$ & Carcinosarcoma & 1 & Yes \\
\hline 4 & 56 & 23 & IB & $2+/ 13$ & $1 / 15,2 / 6$ & $0 / 16$ & Papillary serous & 3 & No \\
\hline 5 & 72 & 21.5 & IA & $1+/ 34$ & $7 / 14$ & $2+/ 17$ & Papillary serous & 3 & No \\
\hline 6 & 70 & 38.5 & IIIA & $2+/ 9$ & $1 / 8,1 / 23$ & $0 / 10$ & Papillary serous & 3 & Yes \\
\hline 7 & 76 & 23.2 & IB & $2+/ 14$ & $5 / 9,2 / 2$ & $0 / 5$ & Papillary serous & 3 & Yes \\
\hline Mean & 65.6 & 27.7 & & $2.1 / 16.4$ & $2.7 / 9.9$ & $0.3+/ 15.2$ & & & \\
\hline
\end{tabular}

\#Evaluated by magnetic resonance imaging. N+/NT: number of positive lymph nodes/number of lymph nodes removed; PAL: Para-Aortic Lymphadenectomy; PL: pelvic lymphadenectomy; NP: not performed; BMI: body mass index; LVSI: lymphovascular space invasion.

Table IV. Principal studies on the performance of 18 F-fluorodeoxyglucose positron-emission tomography integrated with computed tomography for assessing para-aortic lymph nodes.

\begin{tabular}{|c|c|c|c|c|c|c|c|c|c|c|}
\hline \multirow{3}{*}{ Study } & \multirow{3}{*}{ Patients, $\mathrm{n}$} & \multicolumn{2}{|c|}{$\mathrm{PAL}, \mathrm{n}$} & \multirow{2}{*}{\multicolumn{2}{|c|}{ Distribution, n (\%) }} & \multirow{2}{*}{\multicolumn{5}{|c|}{ Performance of ${ }^{18}$ FDG PET-CT, $\%$}} \\
\hline & & \multirow[t]{2}{*}{ Total } & \multirow[t]{2}{*}{ Positive } & & & & & & & \\
\hline & & & & Type 1 & Type 2 & Sensitivity & Specificity & PPV & NPV & Accuracy \\
\hline Suzuki et al., 2007 (11) & 30 & 19 & 1 & $29(97 \%)$ & $1(3 \%)$ & 0 & 100 & 0 & 94.7 & 94.7 \\
\hline Park et al., 2008 (12) & 53 & 31 & 7 & $32(60 \%)$ & $21(40 \%)$ & 57.1 & 87.5 & 57.1 & 87.5 & 80.6 \\
\hline Kitajima et al., 2008 (13) & 40 & 34 & $\mathrm{NC}$ & $37(93 \%)$ & $3(7 \%)$ & 51.7 & 99.4 & 83.3 & 97.3 & 96.8 \\
\hline Crivellaro et al., 2013 (14) & 76 & 15 & 6 & $66(87 \%)$ & $10(13 \%)$ & 85.7 & 96 & 87.5 & 96.3 & 94.3 \\
\hline Gholkar et al., 2014 (15) & 20 & 13 & 1 & $15(75 \%)$ & $5(25 \%)$ & 100 & 66.7 & 20 & 100 & 69.2 \\
\hline Atri et al., 2017 (16) & 160 & 160 & 23 & NR & & 65 & 88 & 48.4 & 93.8 & 85 \\
\hline Our study & 81 & 35 & 14 & $14(40 \%)$ & $21(60 \%)$ & 50 & 100 & 100 & 75 & 80 \\
\hline
\end{tabular}

NR: Not reported; PAL: para-aortic lymphadenectomy.

patients with serous adenocarcinoma or endometrioid adenocarcinoma (18-20). Clear-cell carcinomas seem to prefer the glutaminolysis pathway over glycolysis, resulting in lower ${ }^{18}$ F-FDG concentrations in cells and a weaker signal (19).

In our study, 20 (24.7\%) out of 81 patients had metastases (stage IVB) discovered on the basis of a positive ${ }^{18}$ FDG PETCT result. This examination therefore avoided the need for irrelevant and potentially invasive lymph-node surgery. Kim et al. showed that ${ }^{18}$ FDG PET-CT had an excellent performance for the detection of distal metastases, with a sensitivity of $92.9 \%$, specificity of $98.9 \%$, PPV of $81.3 \%$, NPV of $99.6 \%$ and an accuracy of $98.6 \%$ (21). They thus proposed an algorithm in which ${ }^{18}$ FDG PET-CT was the first examination performed to detect distal metastases and evaluate lymph-node involvement. MRI, on the other hand, was used only for the evaluation of tumor characteristics, such as the degree of myometrial invasion, in particular. In their meta-analysis of seven studies performed in 2013, Kakhki et al. found that ${ }^{18}$ FDG PET-CT had a sensitivity of $95.7 \%$ and specificity of $95.4 \%$ for the detection of distant metastasis (22).
The sampling of sentinel lymph nodes (SLN) may be an alternative to imaging that is less drastic than lymphadenectomy. The French SENTI-ENDO study, which evaluated the feasibility of SLN biopsy in endometrial cancer, reported a detection rate of $89 \%$ [95\% confidence intervaI $(\mathrm{CI})=82-93 \%$ ] by double labeling (patented blue and 99technetium) (23). In their study, the sensitivity of the technique was $84 \%(95 \% \mathrm{CI}=62-95 \%)$ and the NPV was $97 \%$ (95\% CI=91-99\%). They reported three false negatives, all corresponding to type 2 lesions, confirming the singularity of histological type 2 .

It is unclear whether the search for SLN would have identified the affected PA lymph nodes not picked up by PET in our series. An evaluation of the characteristics of the false negatives in our study showed most to correspond to patients with type 2 lesions, with a small number of positive lymph nodes, invasion of a few millimeters, and mostly negative pelvic lymphadenectomies. This result is discordant with published findings. Widschwendter et al. reported that only $3 \%$ of isolated PA lesions were affected, with no pelvic involvement. However, the proportion of type 2 tumors was low (10\%) (24). Soliman 
et al. evaluated the performance of SNL in high-risk endometrial cancers. They reported a promising sensitivity of $95 \%$, with a false-negative rate of $5 \%$. Only one patient had PA involvement, with no pelvic involvement (25). However, the low rate of PA lymph-node involvement in this high-risk population and the small number of lymph nodes removed necessitate confirmation of the utility of SLN in high-risk endometrial cancer. A multicenter French study (SENTIRAD, Identifier: NCT02598219) is currently underway.

Our study had several limitations, including the small number of participants and the absence of information about the size of some lymph-node lesions, despite the importance of this element. Indeed, the poor sensitivity of ${ }^{18}$ FDG PET-CT probably reflects the need for a sufficient number of neoplastic cells to induce ${ }^{18}$ F-FDG hypermetabolism. In our series, reassessment of the 15 false-negative lymph nodes revealed lesions of less than $6 \mathrm{~mm}$ in diameter for $80 \%$ of these nodes. Kitajima et al. showed that the sensitivity of ${ }^{18}$ FDG PET-CT depended on lymph node size, with values of 13 to $17 \%$ for lymph nodes of less than $4 \mathrm{~mm}, 67 \%$ for lymph nodes of 5 to $9 \mathrm{~mm}$, and 97 to $100 \%$ for lymph nodes of more than $10 \mathrm{~mm}$ in diameter $(13,26)$. Park et al. focused on the performance of ${ }^{18}$ FDG PET-CT for lymph nodes giving negative results on MRI. They showed that true positives had a mean size of $8 \mathrm{~mm}$ for the long axis and $5 \mathrm{~mm}$ for the minor axis, whereas the false-positive lymph nodes had a mean size of $6 \mathrm{~mm}$ for the long axis and $3 \mathrm{~mm}$ for the minor axis (27).

In conclusion, ${ }^{18}$ FDG PET-CT can detect a metastasis in approximately $25 \%$ of cases of high-risk endometrial cancer. Given its high specificity in PA lymph-node evaluation, a positive PET scan might make it possible to avoid PAL, that would be advantageous given that the actual therapeutic value of lymphadenectomy remains unclear. In cases of high-risk endometrioid endometrial cancer and in patients with high levels of comorbidity, the high accuracy of PET might help guide decisions as to whether or not to perform PAL. In cases of ${ }^{18}$ FDG-negative PET-CT for type 1 lesions, SLN evaluation may be a viable alternative to PAL. For type 2 lesions, ${ }^{18} \mathrm{FDG}$ PET-CT cannot currently replace PAL because of the risk of false negatives. However, more highly powered prospective studies are required to confirm these results.

\section{Conflicts of Interest}

The Authors declare no conflicts of interest in regard to this study.

\section{Authors' Contributions}

Maxime Legros, François Margueritte, Tristan Gauthier are the principal authors and investigator of this study. Aymeline Lacorre, Yves Aubard, and Tristan Gauthier carried out all surgical procedures. Alexandru Ceuca interpreted all MRI. Jacques Monteil interpreted all ${ }^{18}$ FDG PET-CT. Camille Sallèe and Antoine Tardieu participated in data collection. Valère Mbou interpreted all pathology analyses. Elise Deluche participated in multidisciplinary medical team meetings for the management of patients. All Authors helped to evaluate and edit the manuscript.

\section{References}

1 Projection de l'incidence et de la mortalite par cancer en France metropolitaine en 2015/2015/Maladies chroniques et traumatismes/ Rapports et synthèses/Publications et outils/ Accueil. Available from: http://invs.santepubliquefrance.fr/ Publications-et-outils/Rapports-etsyntheses/Maladies-chroniques-et-traumatismes/2015/Projection-de1-incidence-et-de-la-mortalite-par-cancer-en-France-metropolitaineen-2015, last accessed January 18, 2019.

2 Koskas M, Bassot K, Graesslin O, Aristizabal P, Barranger E, Clavel-Chapelon F, Haddad B, Luton D, Darai E and Rouzier R: Impact of lymphovascular space invasion on a nomogram for predicting lymph node metastasis in endometrial cancer. Gynecol Oncol 129: 292-297, 2013. PMID: 23480871, DOI: 10.1016/j.ygyno.2013.02.027

3 Baekelandt MM, Castiglione M and ESMO Guidelines Working Group: Endometrial carcinoma: ESMO clinical recommendations for diagnosis, treatment and follow-up. Ann Oncol 20(Suppl 4): 29-31, 2009. PMID: 19454455, DOI: 10.1093/annonc/mdp120

4 C Cancer de l'endomètre Collection Recommandations \& Référentiels, INCa, Boulogne-Billancourt, November 2010.

5 Agar N, Philippe A-C, Bourdel N, Rabischong B, Canis M, Le Bouedec G, Mulliez A, Dauplat J and Pomel C: Les lymphadenectomies dans le cancer de l'endomètre, bilan après 4 ans de pratique, doit-on poursuivre? Bull Cancer 102: 428-435, 2015. PMID: 25956349, DOI: 10.1016/j.bulcan.2015.04.001

6 May K, Bryant A, Dickinson HO, Kehoe S and Morrison J: Lymphadenectomy for the management of endometrial cancer. Cochrane Database Syst Rev: CD007585, 2010. PMID: 20091639, DOI: 10.1016/j.bulcan.2015.04.001

7 Colombo N, Creutzberg C, Amant F, Bosse T, González-Martín A, Ledermann J, Marth C, Nout R, Querleu D, Mirza MR, Sessa C and ESMO-ESGO-ESTRO Endometrial Consensus Conference Working Group: ESMO-ESGO-ESTRO Consensus Conference on Endometrial Cancer: Diagnosis, treatment and follow-up. Ann Oncol 27: 16-41, 2016. PMID: 26634381, DOI: 10.1093/annonc/mdv484

8 de Boer SM, Powell ME, Mileshkin L, Katsaros D, Bessette P, Haie-Meder C, Ottevanger PB, Ledermann JA, Khaw P, Colombo A, Fyles A, Baron M-H, Jürgenliemk-Schulz IM, Kitchener HC, Nijman HW, Wilson G, Brooks S, Carinelli S, Provencher D, Hanzen C, Lutgens LCHW, Smit VTHBM, Singh N, Do V, D'Amico R, Nout RA, Feeney A, Verhoeven-Adema KW, Putter H, Creutzberg CL, McCormack M, Whitmarsh K, Allerton R, Gregory D, Symonds P, Hoskin PJ, Adusumalli M, Anand A, Wade R, Stewart A, Taylor W, Kruitwagen RFPM, Hollema H, Pras E, Snyers A, Stalpers L, Jobsen JJ, Slot A, Mens J-WM, Stam TC, Van Triest B, Van der Steen - Banasik EM, De Winter KAJ, Quinn MA, Kolodziej I, Pyman J, Johnson C, Capp A, Fossati R, Gribaudo S, Lissoni AA, Ferrero A, Artioli G, Davidson C, McLachlin CM, Ghatage P, Rittenberg PVC, Souhami L, Thomas G, Duvillard P, Berton-Rigaud D and Tubiana-Mathieu $\mathrm{N}$ : Adjuvant chemoradiotherapy versus radiotherapy alone for women with high-risk endometrial cancer (PORTEC-3): Final results of an international, open-label, multicentre, randomised, phase 3 trial. Lancet Oncol 19: 295-309, 2018. PMID: 29449189, DOI: $10.1016 / \mathrm{S} 1470-2045(18) 30079-2$ 
9 Gouy S, Morice P, Narducci F, Uzan C, Gilmore J, KolesnikovGauthier H, Querleu D, Haie-Meder C and Leblanc E: Nodalstaging surgery for locally advanced cervical cancer in the era of PET. Lancet Oncol 13: e212-220, 2012. PMID: 22554549, DOI: $10.1016 / \mathrm{S} 1470-2045(12) 70011-6$

10 Gouy S, Morice P, Narducci F, Uzan C, Martinez A, Rey A, Bentivegna E, Pautier P, Deandreis D, Querleu D, Haie-Meder $\mathrm{C}$ and Leblanc E: Prospective multicenter study evaluating the survival of patients with locally advanced cervical cancer undergoing laparoscopic para-aortic lymphadenectomy before chemoradiotherapy in the era of positron-emission tomography imaging. J Clin Oncol Off J Am Soc Clin Oncol 31: 3026-3033, 2013. PMID: 23857967, DOI: 10.1200/JCO.2012.47.3520

11 Suzuki R, Miyagi E, Takahashi N, Sukegawa A, Suzuki A, Koike I, Sugiura K, Okamoto N, Inoue T and Hirahara F: Validity of positron emission tomography using fluoro-2deoxyglucose for the preoperative evaluation of endometrial cancer. Int J Gynecol Cancer 17: 890-896, 2007. PMID: 17343574, DOI: 10.1111/j.1525-1438.2007.00859.x

12 Park J-Y, Kim EN, Kim D-Y, Suh D-S, Kim J-H, Kim Y-M, Kim Y-T and Nam J-H: Comparison of the validity of magnetic resonance imaging and positron -emission tomography/computed tomography in the preoperative evaluation of patients with uterine corpus cancer. Gynecol Oncol 108: 486-492, 2008 PMID: 18201753, DOI: 10.1016/j.ygyno.2007.11.044

13 Kitajima K, Murakami K, Yamasaki E, Fukasawa I, Inaba N, Kaji Y and Sugimura K: Accuracy of ${ }^{18} \mathrm{~F}-\mathrm{FDG}$ PET/CT in detecting pelvic and para-aortic lymph node metastasis in patients with endometrial cancer. Am J Roentgenol 190: 16521658, 2008. PMID: 18492920, DOI: 10.2214/AJR.07.3372

14 Crivellaro C, Signorelli M, Guerra L, De Ponti E, Pirovano C, Fruscio R, Elisei F, Montanelli L, Buda A and Messa C: Tailoring systematic lymphadenectomy in high-risk clinical early stage endometrial cancer: The role of ${ }^{18} \mathrm{~F}-\mathrm{FDG} \mathrm{PET} / \mathrm{CT}$. Gynecol Oncol 130: 306-311, 2013. PMID: 23707673, DOI: 10.1016/j.ygyno.2013.05.011

15 Gholkar NS, Saha SC, Prasad G, Bhattacharya A, Srinivasan R and Suri V: The Accuracy of integrated (18)F fluorodeoxyglucosepositron-emission tomography/computed tomography in detection of pelvic and para-aortic nodal metastasis in patients with high risk endometrial cancer. World J Nucl Med 13: 170-177, 2014. PMID: 25538488, DOI: $10.4103 / 1450-1147.144817$

16 Atri M, Zhang Z, Dehdashti F, Lee SI, Marques H, Ali S, Koh W-J, Mannel RS, DiSilvestro P, King SA, Pearl M, Zhou X, Plante M, Moxley KM and Gold M: Utility of PET/CT to evaluate retroperitoneal lymph node metastasis in high-risk endometrial cancer: Results of ACRIN 6671/GOG 0233 Trial. Radiology 283: 450-459, 2017. PMID: 28051912, DOI: 10.1148/radiol.2016160200

17 Yahata T, Yagi S, Mabuchi Y, Tanizaki Y, Kobayashi A, Yamamoto M, Mizoguchi M, Nanjo S, Shiro M, Ota N, Minami $\mathrm{S}$, Terada $\mathrm{M}$ and Ino K: Prognostic impact of primary tumor SUVmax on preoperative ${ }^{18}$ F-fluoro-2-deoxy-D-glucose positronemission tomography and computed tomography in endometrial cancer and uterine carcinosarcoma. Mol Clin Oncol 5: 467-474, 2016. PMID: 27703679, DOI: 10.3892/ mco.2016.980

18 Konishi H, Takehara K, Kojima A, Okame S, Yamamoto Y, Shiroyama Y, Yokoyama T, Nogawa $\mathrm{T}$ and Sugawara $\mathrm{Y}$ : Maximum standardized uptake value of fluorodeoxyglucose positron-emission tomography/computed tomography is a prognostic factor in ovarian clear cell adenocarcinoma. Int $\mathbf{J}$ Gynecol Cancer 24: 1190-1194, 2014. PMID: 24987918, DOI: 10.1097/IGC.0000000000000180

19 Sato M, Kawana K, Adachi K, Fujimoto A, Taguchi A, Fujikawa T, Yoshida M, Nakamura H, Nishida H, Inoue T, Ogishima J, Eguchi S, Yamashita A, Tomio K, Arimoto T, Wada-Hiraike O, Oda $\mathrm{K}$, Nagamatsu T, Osuga $\mathrm{Y}$ and Fujii $\mathrm{T}$ : Low uptake of fluorodeoxyglucose in positron-emission tomography/computed tomography in ovarian clear cell carcinoma may reflect glutaminolysis of its cancer stem cell-like properties. Oncol Rep 37: 1883-1888, 2017. PMID: 28112360 , DOI: $10.3892 /$ or. 2017.5398

20 Tanizaki Y, Kobayashi A, Shiro M, Ota N, Takano R, Mabuchi Y, Yagi S, Minami S, Terada M and Ino K: Diagnostic value of preoperative SUVmax on FDG-PET/CT for the detection of ovarian cancer. Int J Gynecol Cancer 24: 454-460, 2014. PMID: 24463640, DOI: 10.1097/IGC.0000000000000074

21 Kim HJ, Cho A, Yun M, Kim YT and Kang WJ: Comparison of FDG PET/CT and MRI in lymph node staging of endometrial cancer. Ann Nucl Med 30: 104-113, 2016. PMID: 26546334, DOI: $10.1007 / \mathrm{s} 12149-015-1037-8$

22 Kakhki VRD, Shahriari S, Treglia G, Hasanzadeh M, Zakavi SR, Yousefi Z, Kadkhodayan S and Sadeghi R: Diagnostic performance of fluorine 18 fluorodeoxyglucose positronemission tomography imaging for detection of primary lesion and staging of endometrial cancer patients: Systematic review and meta-analysis of the literature. Int $\mathrm{J}$ Gynecol Cancer 23: 1536-1543, 2013. PMID: 24172090, DOI: 10.1097/IGC. 0000000000000003

23 Ballester M, Dubernard G, Lecuru F, Heitz D, Mathevet P, Marret H, Querleu D, Golfier F, Leblanc E, Rouzier R and Daraï E: Detection rate and diagnostic accuracy of sentinel-node biopsy in early stage endometrial cancer: a prospective multicentre study (SENTI-ENDO). Lancet Oncol 12: 469-476, 2011. PMID: 21489874, DOI: 10.1016/S1470-2045(11)70070-5

24 Widschwendter P, Bauer E, De Gregorio N, Bekes I, Janni W, Scholz C and Friedl TWP: Influence of prognostic factors on lymph node involvement in endometrial cancer: a single-center experience. Int J Gynecol Cancer 28: 1145-1152, 2018. PMID: 29757871, DOI: 10.1097/IGC.0000000000001290

25 Soliman PT, Westin SN, Dioun S, Sun CC, Euscher E, Munsell MF, Fleming ND, Levenback C, Frumovitz M, Ramirez PT and Lu KH: A prospective validation study of sentinel lymph node mapping for high-risk endometrial cancer. Gynecol Oncol 146: 234-239, 2017. PMID: 28528918, DOI: 10.1016/ j.ygyno.2017.05.016

26 Kitajima K, Murakami K, Yamasaki E, Kaji Y and Sugimura K: Accuracy of integrated FDG-PET/contrast-enhanced CT in detecting pelvic and paraaortic lymph node metastasis in patients with uterine cancer. Eur Radiol 19: 1529-1536, 2009. PMID: 19184037, DOI: 10.1007/s00330-008-1271-8

27 Park J-Y, Lee JJ, Choi HJ, Song IH, Sung CO, Kim HO, Chae S-Y, Kim Y-T and Nam J-H: The value of preoperative positron emission tomography/computed tomography in node-negative endometrial cancer on magnetic resonance imaging. Ann Surg Oncol 24(8): 2303-2310, 2017. PMID: 28550488, DOI: $10.1245 / \mathrm{s} 10434-017-5901-8$

Received January 2, 2019

Revised January 18, 2019

Accepted January 22, 2019 